\title{
Estratégias para workshops focados no desenvolvimento de artefatos críticos.
}

Strategies for workshops focused on the development of critical artifacts.

LORENZ, Bruno; Mestre; Universidade do Vale Rio dos Sinos (UNISINOS)

lorenz.bruno@gmail.com

SCALETSKY, Celso Carnos; Doutor; Universidade do Vale Rio dos Sinos (UNISINOS)

celsocs@unisinos.br

\section{Resumo}

Nas últimas décadas, novas compreensões sobre o design passaram a considerar diferentes aspectos a ele relacionados, associados às qualidades imateriais da atividade e de seus produtos. Uma dessas abordagens é a da prática crítica, que se utiliza de estratégias retóricas baseadas em narrativas, poéticas, provocações e metáforas na criação de artefatos preocupados em instigar debates sobre os valores e crenças que estruturam a sociedade. O objetivo deste artigo é o de discutir o workshop como método para o desenvolvimento de artefatos críticos. Para isso, propõese três workshops em que designers projetavam artefatos críticos e eram entrevistados sobre as dinâmicas de tal atividade. Nos resultados, sugerimos cinco diretrizes para a facilitação de workshops voltados ao desenvolvimento de artefatos críticos: i) definir procedimentos de entrega estritos; ii) oferecer métodos e ferramentas generativas; iii) facilitar a colaboração entre os projetistas; iv) utilizar linguagem clara e compreensível e v) facilitar o uso da teoria como validação e como gatilho.

Palavras Chave: prática crítica; workshop; artefato.

\section{Abstract}

In the last decades, new understandings on the design began to consider different aspects related to it, associated to the immaterial qualities of the activity and its products. One of these approaches is that of critical practice, which uses rhetorical strategies based on narratives, poetics, provocations and metaphors in the creation of artifacts concerned with instigating debates about the values and beliefs that structure society. The purpose of this article is to discuss the workshop as a method for the development of critical artifacts. For this, we propose three workshops in which designers designed and were interviewed about the dynamics of such activity. In the results, we suggest five guidelines for facilitating workshops aimed at developing critical artifacts: defining strict delivery procedures; offer generative methods and tools; facilitate collaboration between designers; use clear and understandable language and facilitate the use of theory as validation and as a trigger.

Keywords: critical practice; workshop; artifact. 


\section{Introdução}

Até a metade do século passado, "Design" era comumente entendido como uma atividade projetual que atendia a indústria e que se focava nos processos e na produção em massa de bens de consumo. Nas últimas décadas, esse entendimento passou a considerar também outros aspectos do fenômeno, associados às qualidades imateriais da atividade e de seus produtos - construção de significados, impacto dos artefatos nas emoções humanas e a melhor compreensão do espaço problema-solução, por exemplo. (CARDOSO, 2012; FLUSSER, 2007; KRIPPENDORFF, 2005; DORST, 2008). No entanto, mesmo que a concepção sobre design venha gradualmente sendo expandida, observa-se que tal paradigma não é o único modelo epistemológico considerado por praticantes e pesquisadores do campo.

O presente artigo se interessa no desenvolvimento de artefatos criados a partir de uma abordagem que entendemos ser bastante peculiar no design: a da prática crítica. (MALPASS, 2017). Ao invés do enfoque voltado ao desenvolvimento de bens de consumo, essa prática se utiliza de estratégias retóricas baseadas em narrativas, poéticas, provocações e metáforas na criação de artefatos críticos, criados para instigar debates sobre valores, crenças e comportamentos que estruturam a sociedade. (DUNNE, 2005; DUNNE; RABY, 2013; MALPASS, 2017). Essa é uma abordagem que rejeita o entendimento do design como uma prática focada exclusivamente em ganhos financeiros e tecnológicos, e que se concentra na busca por perguntas, anteriormente à busca por respostas. (MAZÉ; REDSTROM, 2007; OZKARAMANLI; DESMET, 2016). Abaixo, a figura 1 apresenta exemplos de artefatos críticos:

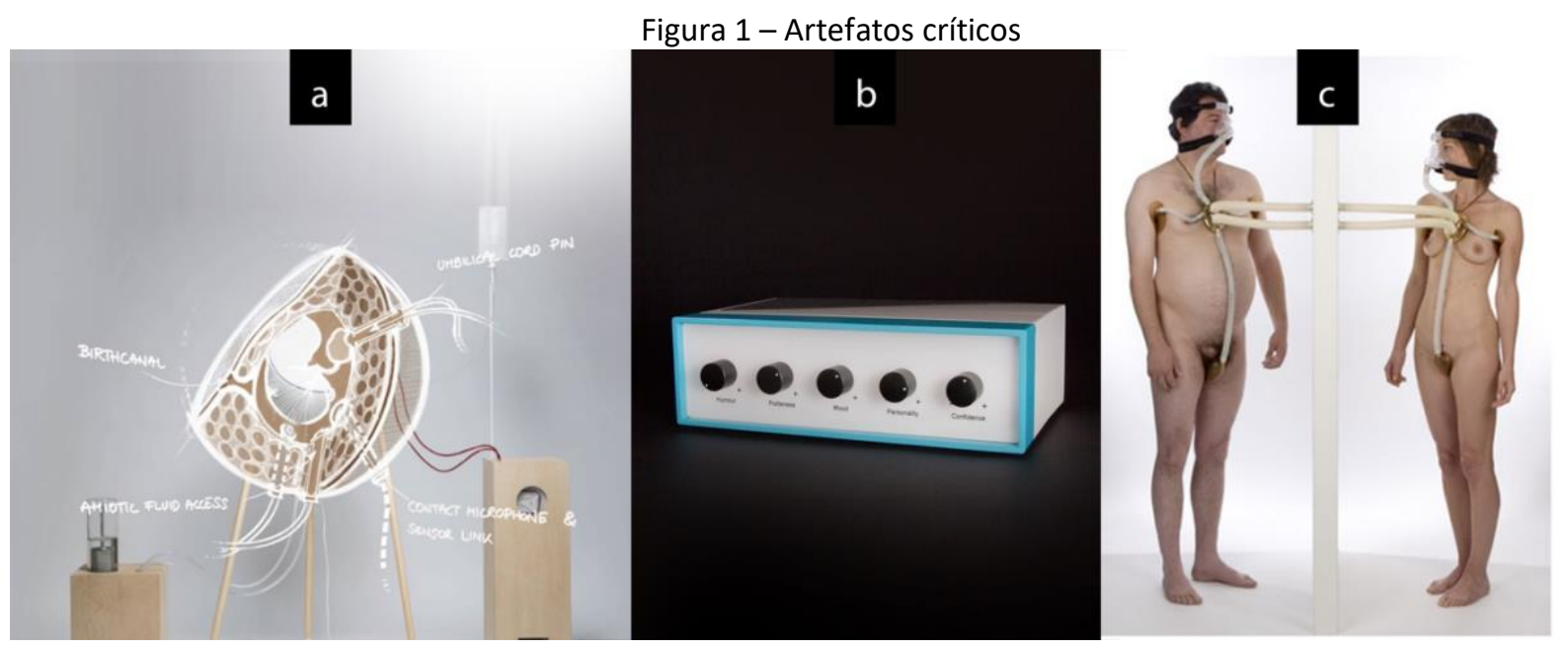

Fonte: a) Billie Rehwald ${ }^{1}$, b) Estúdio Superflux²; c) James Auger e Jimmy Loizeau³.

No projeto Ava Ectogenesis (a), a designer Billie Rehwald imagina como seria um mundo em que a gravidez passa a acontecer fora do corpo humano, propondo o desenho de um útero artificial que acaba por levantar questionamentos éticos, morais e tecnológicos acerca da gestação. Com Friends Electric, o Estúdio Superflux explora os impactos de inteligências artificiais que simulam perfeitamente a voz humana e que são introduzidas em objetos do cotidiano. $O$ aparelho

\footnotetext{
${ }^{1}$ Disponível em <http://www.billierehwald.com/avaectogenesis>. Acesso em 17 jun 2018.

${ }^{2}$ Disponível em <http://superflux.in/index.php/work/friends-electric>. Acesso em 17 jun 2018.

${ }^{3}$ Disponível em <http://www.auger-loizeau.com/projects/smell>. Acesso em 17 jun 2018.
} 
apresentado em (b) faz ligações telefônicas para bancos, com o objetivo de cancelar serviços ou negociar valores. Os botões pretos delimitam as características que a voz artificial terá (mais ou menos humor, irritação ou diplomacia, por exemplo). Já com o projeto Smell+ (c), os designers James Auger e Jimmy Loizeau foram contratados pela empresa Phillips para investigar o potencial do olfato em contextos domésticos e sociais. A imagem representa uma das propostas materializadas, onde a dupla propõe um artefato que poderia auxiliar pessoas a encontrarem pares românticos ideais a partir somente de interações olfativas.

O que se percebe nos exemplos acima é a natureza questionadora dos artefatos propostos, em que os designers - sejam eles acadêmicos, sejam eles profissionais atuantes no mercado buscam não somente a criação de um objeto que será produzido em massa, mas sim, debater quais seriam os impactos sociais, éticos e culturais de tais tecnologias quando inseridas no cotidiano. Assim, o que se busca com a prática crítica é o debate, a reflexão e a inclusão da sociedade nessas discussões que, tendo contato com tais propostas, pode compreender como a tecnologia afeta o cotidiano e incorpora políticas que comumente não são explícitas em um contexto de consumo.

Assim, emergem métodos de projeto que, sem negar a materialidade do artefato, se voltam para dinâmicas discursivas, experimentais e generativas para alcançar seus objetivos. (MALPASS, 2013). Aos poucos, emergem estudos relacionados à natureza dessa abordagem, focados, principalmente, em aspectos epistêmicos e conceituais da prática. (AUGER, 2013; BARDZELL et al., 2014; FERRI et al., 2014; MALPASS, 2017). O campo da prática crítica, no entanto, ainda carece de estudos que formem um arcabouço teórico bem estruturado, principalmente no que concerne à suas práticas metodológicas. (MALPASS, 2017). Assim, este artigo busca contribuir para tal lacuna teórica, propondo a estruturação de atividades voltadas ao desenvolvimento de artefatos críticos.

Tendo em vista que estamos preocupados em analisar a atividade projetual que dá conta de desenvolver artefatos críticos, sendo possível acompanhar e registrar os caminhos e resultados de projetos dessa natureza, escolheu-se o workshop como método para atender a tais demandas. Para Scaletsky (2008), o workshop se caracteriza por um espaço de criação intensiva, que valoriza a criatividade e a experimentação. Nela, é possível desenvolver cenários de projeto, alcançar novos conceitos e olhares para o que se estuda e até mesmo materializar as primeiras ideias que atendem aos briefings propostos no início da atividade. Assim, uma característica importante de um workshop é a sua flexibilidade, o que permite que diferentes técnicas e métodos possam ser utilizados em um período delimitado de tempo. (HALPERN \& COSTA, 2017).

A flexibilidade, no entanto, é uma qualidade ambígua: do mesmo modo que aceita todo tipo de estrutura, torna-se também genérica em atividades específicas. Queremos aqui propor estratégias específicas para a construção de artefatos críticos. Ou seja, queremos atender às necessidades idiossincráticas dessa categoria particular de produto.

Desse modo, nosso objetivo neste artigo é o de discutir o workshop como método para o desenvolvimento de artefatos críticos. Queremos compreender quais são as características e dinâmicas que facilitam ou dificultam essa abordagem projetual particular, a fim de discutir e sugerir diretrizes para que atividades futuras da mesma natureza possam ser beneficiadas. Frisamos que os workshops discutidos fizeram parte da dissertação de mestrado de um dos autores do artigo. (LORENZ, 2018).

Na próxima seção, explicitamos o método adotado, composto por três workshops de prática projetual crítica, seguidos de entrevistas com os participantes. Na terceira seção, revelamos os 
resultados alcançados a partir das observações e de análises dos conteúdos das entrevistas. Na quarta e última seção, discutimos os resultados e sugerimos diretrizes que podem ser adotadas para novas atividades de mesma natureza, além das reflexões finais e sugestão de estudos futuros.

\section{Método}

Os workshops da pesquisa de Lorenz (2018) propunham a construção de artefatos críticos a fim de explorar problemas de pesquisa acadêmicos. Ou seja, buscava-se compreender como esses artefatos e o próprio processo de construção deles impactava na estruturação de problemas de pesquisa de projetos de mestrado, por exemplo. Para isso, a atividade projetual proposta nos workshops era sucedida por entrevistas em grupos focais com os participantes, para que se pudesse compreender como a atividade projetual de artefatos críticos impactou na compreensão de seus próprios problemas de pesquisa.

Tendo em vista a necessidade da análise de exercícios projetuais voltados à reflexão sobre problemas de pesquisa acadêmicos, os sujeitos convidados a participarem dos workshops foram selecionados a partir de duas características: i) Projetistas com experiência e ii) Mestrandos em design, familiarizados e envolvidos com o processo e os pormenores da construção de projetos de pesquisa acadêmicos, bem como de problemas de pesquisa. Foram selecionados oito designers que participaram dos três workshops a partir de suas disponibilidades de agenda.

O Quadro 1 revela como foi feita a separação. Os nomes são fictícios, para fins de privacidade.

Quadro 1 - Participantes dos workshops

\begin{tabular}{ll}
\hline Workshop & Participantes \\
\hline workshop 1 & Fabiana, designer gráfica, primeiro semestre do mestrado \\
\hline workshop 2 & $\begin{array}{l}\text { Raissa, designer gráfica, quarto semestre do mestrado } \\
\text { Antero, designer gráfico e de produto, terceiro semestre do mestrado } \\
\text { Pablo, designer gráfica, terceiro semestre do mestrado }\end{array}$ \\
\hline workshop 3 & $\begin{array}{l}\text { Jorge, designer gráfica, segundo semestre do mestrado } \\
\text { Brenda, designer gráfica, terceiro semestre do mestrado } \\
\text { William, designer gráfica, primeiro semestre do mestrado } \\
\text { Natan, designer gráfica, terceiro semestre do mestrado }\end{array}$ \\
\hline
\end{tabular}

Fonte: autor

Ao levar em consideração que os participantes do workshop não eram familiarizados com a prática crítica, considerou-se necessário desenvolver um kit de sensibilização com os seguintes materiais: (i) um vídeo sobre a prática crítica; (ii) uma cartilha provocativa e (iii) uma apresentação online com exemplos sobre as três abordagens da Malpass (2017) ${ }^{4}$.

\footnotetext{
${ }^{4}$ Associativa, Especulativa e Dilemática. Em resumo: a abordagem Associativa busca problematizar as diretrizes invisíveis que direcionam as práticas do design voltado ao mercado. A Especulativa dá conta de especular os impactos sociais, econômicos, culturais e afins de novas descobertas tecnológicas. A Dilemática são leituras distópicas e violentas de realidades sociais contemporâneas.
} 
$\mathrm{O}$ vídeo ${ }^{5}$ tem duração de seis minutos e apresentava conceitos gerais sobre a prática crítica, parte do manifesto A/B (DUNNE \& RABY, 2013), as três abordagens de Malpass (2017) e considerações sobre o papel do artefato em pesquisas dessa natureza. Esperava-se que os participantes pudessem compreender as particularidades dessa maneira de fazer design, além de começar, aos poucos, a relacionar essa perspectiva com seus próprios problemas de pesquisa.

A cartilha provocativa consistiu em uma espécie de caderno dobrável em tamanho A3, composto por diversas perguntas relacionadas ao projeto de pesquisa do indivíduo convidado. Este material foi inspirado pelo Cultural Probes (BOEHNER et al., 2012), método de coleta de informações próprio do design, que se destaca por sua capacidade de acessar o universo particular de determinado contexto, prescindindo da presença do pesquisador para tal.

A figura 2 apresenta o material: a) pacote fechado, contendo a cartilha; b) cartilha fechada e c) cartilha aberta.

Figura 2 - Cartilha Provocativa

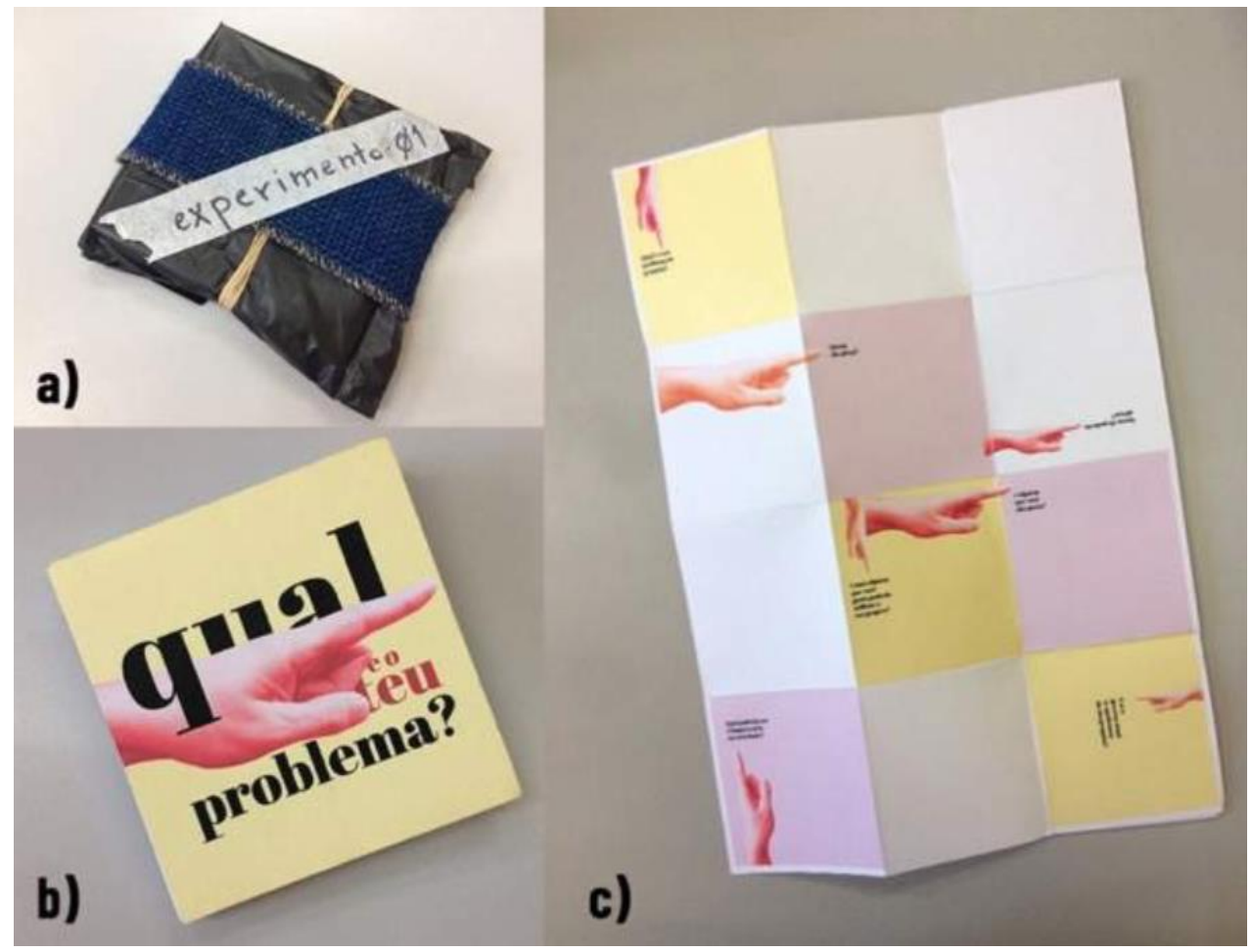

Fonte: autor

O objetivo da cartilha foi o de propor provocações que auxiliassem os participantes da pesquisa a exercer uma reflexão crítica sobre seus próprios problemas de pesquisa: (1) Qual é o seu problema de pesquisa?; (2) Quem (ou o que) ele afeta?; (3) Quem mais ele poderia afetar?; (4) Como alguém que você gosta poderia se apoderar dos resultados de sua pesquisa?; (5) E alguém que você não gosta?; (6) Qual poderia ser o impacto dos resultados da sua pesquisa na sociedade?; (7) E se o governo atual se apoderasse da sua pesquisa?; (8) Quais são os aspectos mais provocativos da sua pesquisa?; (9) Liste três artefatos (existentes ou não) que representem ou poderiam incorporar o

\footnotetext{
${ }^{5}$ Vídeo disponível em: https://www.youtube.com/watch?v=KV5Z2N1d1MU
} 
seu problema de pesquisa de alguma forma.

Os workshops foram realizados em salas equipadas com computadores, mesas e cadeiras modulares e paredes com superfícies que permitem inscrições com marcadores de quadro branco. Aos participantes, foram disponibilizados materiais para desenho (canetas, folhas de papel A3), inspiração (imagens com temas diversos) e modelagem (massas de modelar). As atividades foram gravadas em vídeo por câmeras instaladas em tripés, enquanto celulares gravaram o áudio. Todas as três atividades foram acompanhadas in loco pelos autores da pesquisa, disponíveis também no local para sanar eventuais dúvidas que surgissem durante os exercícios.

O briefing proposto para o workshop foi o seguinte:

"Desenvolver artefatos que explorem a reflexão crítica do seu problema de pesquisa, tendo como ponto de partida elementos relacionados ao problema de pesquisa de sua dissertação. Lembre-se que:

a. É importante que exista a representação de um artefato nesse contexto.

b. A representação desse artefato precisa ser visual: sketches, colagens, renders, storyboards, mapas contextuais, etc.

c. O artefato precisa ter um nome.

d. Priorizem a originalidade e a variedade de propostas à viabilidade.

e. O método de projeto é livre. O mapa mental deve ser desenvolvido na primeira meia hora, com o problema de pesquisa no centro.

f. Tentem utilizar todo o tempo disponível de projeto.

g. Lembrem-se: não existem movimentos certos e ou errados em contextos projetuais".

Durante a atividade projetual, foi dada a liberdade aos participantes para que pudessem se sentar em qualquer lugar da sala. Trabalhando sozinha, Fabiana projetou em silêncio durante todo o tempo. No segundo workshop, Pablo, Antero e Raissa sentaram-se distantes uns dos outros e também trabalharam silenciosos em seus projetos. Os participantes do terceiro workshop decidiram manter-se sentados em volta da mesa onde estavam disponíveis a comida e a bebida. Por se conhecerem previamente, eles conversaram e trocaram ideias durante a atividade.

Após o fim da etapa de atividade projetual, os designers eram convidados a apresentarem suas propostas para o grupo e para o monitor, discorrendo brevemente sobre o conceito do artefato e a relação deste com seu problema de pesquisa. Foi pedido a eles que comunicassem as propostas verbalmente e a partir de seus rascunhos e sketches, sem necessidade de desenvolvimento de slides ou ferramentas mais complexas que pudessem atrapalhar o cronograma proposto.

Ao fim dessa etapa, os designers então formavam um grupo focal para que fosse possível discutir diferentes aspectos da atividade projetual recém exercida. Essa dinâmica foi gravada em áudio e vídeo e analisada a partir da técnica de Análise de Conteúdo.

\section{Resultados}

É importante ressaltar que os vinte e cinco artefatos desenvolvidos ao longo das três sessões não serão apresentados no presente artigo, tendo em vista que o enfoque no trabalho está na discussão do método utilizado para a criação deles. Assim, nessa seção, estão reunidas falas 
relacionadas às dinâmicas do próprio workshop de prática crítica. Busca-se identificar quais são as características da atividade que influenciaram - de maneira benéfica ou não - o andamento da proposta. A partir dessas análises, foi possível identificar e sugerir orientações para aperfeiçoar futuras atividades de natureza similar.

Foram identificadas quatro diferentes categorias: i) tempo disponível, ii) influência dos projetistas / cocriação, iii) facilitação criativa e iv) diretrizes projetuais.

\section{i) Tempo Disponível}

Essa categoria explicita como os participantes perceberam o tempo disponibilizado a eles e como reagiram a tal restrição. Em se tratando de um workshop com prazos delimitados, foi necessário estipular um período de tempo restrito para o exercício da atividade projetual - cerca de 2 h30min.

Brenda comenta sobre a delimitação temporal:

"Eu, se tivesse mais tempo, teria gerado mais alternativas. Fui num processo de representação rápida e mais descrição por palavras mesmo, que para mim é mais fácil".

A fala da pesquisadora revela que uma das maneiras como o tempo influencia em como os designers projetam diz respeito à representação de seus projetos. A designer preferiu dar ênfase ao conceito e às dinâmicas de funcionamento e interação das propostas, utilizando-se de palavras e breves descrições, enquanto a representação visual dos objetos era limitada a desenhos esquemáticos. Este é um movimento que corrobora com a literatura da área (BARDZELL, BARDZELL, 2013), que entende que a discussão crítica é voltada principalmente à interpretação dos conceitos e dos conhecimentos incorporados pelos artefatos (sem ter a necessidade imprescindível de morfologias bem definidas).

Além disso, quando comenta que teria gerado mais alternativas se o tempo disponibilizado fosse maior, Brenda chama atenção para o fato de que o número de artefatos a serem desenvolvidos não estava estipulado no briefing inicial - o que abre espaço para que um número mínimo possa ser delimitado com o objetivo de forçar os designers a serem generativos e criarem opções diversas de objetos, a fim de explorar de maneira mais consistente seus problemas de pesquisa.

Natan foi o primeiro a tomar como finalizada a sua proposta de artefato crítico durante no terceiro workshop - preenchendo o tempo restante com comentários sobre os trabalhos alheios ou sobre assuntos não relacionados ao exercício. Assim, nota-se a necessidade de criar dinâmicas para que os designers utilizem todo o tempo disponível de projeto, efetivamente, projetando. A distração causada por um dos designers pode ser fator de influência na maneira como os outros participantes projetam. Contudo, como será melhor explorado na próxima subcategoria, essa interação entre os participantes nem sempre se mostra prejudicial.

Por fim, destaca-se também a facilidade com que os debates emergem em curtos períodos de tempo, como William deixa explícito em sua fala:

"A gente pensou um negócio aqui nesse tempo que a gente tinha e a gente está debatendo sobre o impacto que foi gerado".

A atividade e o tempo delimitado beneficiam a divisão de períodos e de dinâmicas do 
workshop. Percebeu-se, por exemplo, que novas etapas poderiam ser sugeridas nesses exercícios, cada qual com suas próprias regras e dinâmicas (i.e., etapa de crítica ao projeto dos colegas).

\section{b) Influência dos projetistas / cocriação}

Essa categoria está relacionada à influência que os projetistas exercem uns sobre os outros durante a atividade projetual - sejam elas positivas (i.e., inspiração) ou negativas (i.e., atrapalhar a concentração). Para isso, primeiro é importante dissertar sobre movimentos que influenciaram de alguma forma as dinâmicas dos workshops.

No segundo workshop proposto, Antero, Raíssa e Pablo sentaram-se distantes uns dos outros e projetaram em silêncio. Pablo e Raíssa optaram por trabalhar desenhando em folhas A3, enquanto Antero esquematizou suas propostas nas paredes da sala, à vista de todos. Mesmo assim, não houve nenhum tipo de comunicação entre eles durante o exercício projetual, somente na etapa de apresentação de seus projetos. Notou-se que tais comentários, no entanto, não levaram a algum tipo de alteração ou nova leitura dos artefatos propostos.

No terceiro workshop, Brenda, Jorge, Natan e William trabalharam lado a lado, reunindo-se em volta da mesa onde estavam localizadas as comidas e bebidas disponibilizadas pela organização da atividade. Nesse sentido, percebe-se que mesmo detalhes aparentemente sem importância, como a localização dos alimentos, pode induzir diferentes dinâmicas nesse tipo de atividade.

Ao longo do tempo disponível para projeto, os quatro designers alteraram momentos de trabalho em silêncio e períodos em que conversavam sobre amenidades e sobre questões relacionadas a seus projetos. Em um primeiro momento, considerou-se solicitar para que trabalhassem em silêncio, a fim de não prejudicar a atividade de projeto. Contudo, percebeu-se, ao longo do exercício, uma dinâmica de auxílio e troca de experiências entre os participantes, sendo possível a emergência de ideias e sugestões que posteriormente influenciaram os artefatos desenvolvidos.

Natan, por exemplo, comenta sobre essa influência mútua entre os designers:

"[...] eu presumo que muito do que a gente estava falando influenciou um ao outro de uma forma bem positiva. A gente discutiu ali a questão de ética, aprofundou um pouco. Eu estava pensando em uma coisa e acabei cogitando que aquela coisa não foi a mais correta".

De fato, durante a atividade, Natan e Brenda discorreram sobre o ponto de vista ético no desenvolvimento de artefatos, o que, em uma análise posterior, demonstra influência sobre as decisões projetuais de uma das ideias geradas, o "Caleidoscópio Retórico", como a própria adoção de diferentes lentes para representar os pontos de vista. Nesse sentido, é importante frisar que os designers do terceiro workshop se conheciam previamente, sendo colegas oriundos de diferentes turmas do mesmo programa de pós-graduação em design, o que contribui para uma maior interação entre eles.

Outra influência registrada nas falas está relacionada a dinâmicas não verbais, como evidencia a seguinte fala de Jorge:

"[...] eu ia fazer um óculos, onde tu conseguia entender os conhecimentos dos outros. Só que daí ah... [fazendo sinal de desistência]. Mas daí eu vi o da Brenda e 'Putz, eu podia ter...' [Voltando ao papel e simulando novos desenhos]". 
Assim, ao se deparar com os estudos da designer sentada à sua frente, Jorge sentiu-se inspirado a seguir novos caminhos em seu projeto. Mesmo que não seja possível discernir com exatidão quais foram os resultados práticos desse episódio, percebe-se que a aproximação entre os designers aciona um senso de comparação entre os trabalhos que pode beneficiar o projeto de forma aspiracional.

Para William, encarar o exercício sem preocupar-se com uma atmosfera de concorrência foi importante para o bom andamento de seu exercício:

"Na minha visão, eu não encarei como uma competição (a proximidade com os colegas). Isso me deu uma leveza na hora de pensar. Não vai ter um melhor. Porque parece que 'Vamos eleger um melhor'. Se tem uma situação dessa eu fico cobrando de mim. Será que faria eu pensar melhor? Daí eu fiquei mais tranquilo. Achei muito bom".

Para isso, no entanto, mostra-se essencial buscar estratégias para instaurar um tom colaborativo na atividade, evitando um ambiente explícito de disputa ou concorrência entre os participantes.

\section{c) Facilitação do Projeto}

Essa categoria explora dinâmicas e estratégias que facilitam o desenvolvimento de artefatos críticos. A presente categoria identifica quais foram as premissas e dinâmicas que facilitaram a manifestação de uma aparente liberdade para projetar. Brenda, por exemplo, comenta sobre a atividade:

"[...] acho o contexto bem livre, porque tu podes extrapolar questões que eu gosto de me fazer no dia a dia, de como as coisas podem ser subvertidas, e como as coisas podem ser melhor ou pior cenário delas. É um exercício que particularmente eu gosto de fazer e problematizar em artefatos, então, pra mim, essa dinâmica de projeto eu acho ela bem livre e bem prazerosa".

Ao identificar uma predileção pessoal de Brenda por atividades relacionadas à ressignificação de artefatos, percebe-se que é possível associar o exercício projetual a questões particulares dos designers (i.e., seu próprio projeto de pesquisa), abrindo a possibilidade do organizador do workshop de explorar a relação entre o prazer sentido pelos projetistas durante a o exercício de design e uma possível liberdade projetual que emerge dessa relação.

Outro aspecto relevante diz respeito à obrigação de uma entrega material no fim da atividade, como pode-se identificar na seguinte fala de Natan:

"[...] esse exercício foi bom porque eu repensei tudo que eu já tinha pensado, com a obrigação de chegar em alguma conclusão que eu ainda não tinha. [...] eu achei bom porque eu não tinha a obrigação que a gente tem no mestrado de chegar num resultado espetacular. Então essa liberdade de 'Cara, faz o que tu achar', pra mim foi muito bom."

Quando fala em obrigação, o designer se refere à resposta que ele precisa dar ao briefing proposto no workshop. Ele se atém a uma espécie de contrato social temporário, que garante que irá responder aos requisitos do exercício (i.e., apresentação de três diferentes propostas). Por mais que, à primeira vista, possa parecer contraditório o conceito de obrigação e liberdade projetual, 
essa dinâmica se mostra pertinente. Pode-se afirmar que um workshop funciona como um tensionamento criativo que reúne de um lado a falta de tempo e esta "obrigação" com a possibilidade de construir ligações entre elementos distintos e/ou distantes, o que poderia ser definido como criatividade.

Outra característica que contribui para a facilitação do raciocínio projetual diz respeito à possibilidade de comunicar um conceito específico sem necessariamente precisar materializá-lo completamente, como pode-se observar nessa fala de Brenda que, em seu projeto de pesquisa, envolvia atividades com crianças:

"[...] porque aqui eu assumo que eu tenho muito mais insumos do que eu realmente tenho. Então é muito mais fácil fazer as dinâmicas acontecerem nesse campo especulativo do que quando tu realmente leva elas para as crianças."

Quando fala sobre insumos, Brenda se refere ao acesso a tecnologias e elementos que são imprescindíveis para seus projetos, mas que ela não teria acesso por diferentes motivos: falta de conhecimento prático para execução, por eles ainda não são possíveis de serem desenvolvidos no presente momento, e até mesmo pela falta de recursos financeiros que poderiam tornar a proposta viável. No entanto, ao considerar que a importância dos conceitos e das narrativas se sobrepõe à importância da materialização das propostas, a designer entende que tal característica contribui no desenvolvimento de artefatos críticos.

\section{d) Diretrizes Projetuais}

Essa categoria trata das impressões dos designers sobre as diretrizes projetuais propostas para a atividade do workshop. Ou seja, quais seriam as melhores práticas que poderiam auxiliar os designers nas diversas etapas da atividade. William, por exemplo, chama atenção para a maneira como o briefing é proposto no início do exercício:

"Tendo uma pergunta norte, eu acho que faz sentido ter esse [briefing]... e me chamou atenção, a partir disso, a importância que é pensar a pergunta correta para gerar o debate do workshop, né? Às vezes tu pode matar todo o processo de pensar o 'amanhã' com uma palavra".

Nessa fala, percebe-se novamente a importância dos termos utilizados na orientação do exercício de projeto. Quando William fala sobre "a pergunta correta", ele estava se referindo a um momento do workshop onde, quando questionado pelos designers sobre o briefing apresentado, o autor da presente pesquisa alterou uma palavra do enunciado para auxiliar na explicação da atividade. Em vez de "representar o problema de pesquisa", "explorar o problema de pesquisa" mostrou-se mais pertinente à proposta. Tal substituição parece ter contribuído para a forma como os designers encararam a criação de seus artefatos, tendo em vista que a alteração semântica que decorre desse movimento tornou a diretriz mais clara.

Natan, por sua vez, considera que associar a atividade aos seus próprios problemas de pesquisa foi benéfico para o exercício:

"Eu achei bom isso [associar com as pesquisas de cada um], porque se tu tivesse proposto algo do zero, talvez a gente ficasse muito mais preso em relação a tudo isso aqui, sabe? (apontando para o papel com a teoria crítica). Ao invés de ser um processo que depois a gente chegou a conclusão de que eu usei processo crítico e depois associativo [...]" 
Pela fala do designer, pode-se considerar que a associação entre a atividade e os problemas de pesquisa dos acadêmicos é importante para o bom andamento da atividade, tendo em vista que eles já conhecem as particularidades dos campos e enxergam-se capazes de desenvolver artefatos que não se prendam apenas às definições teóricas da prática crítica.

Nesse sentido, é possível relacionar a fala de Natan com o entendimento da teoria como suporte da prática. Ao associar o exercício criativo com algo já conhecido por ele, o designer se utilizou da teoria como validação de suas propostas, o que sugere que, na ausência de tal associação, o papel da teoria poderia ser de gatilho.

\section{Discussão e considerações finais}

Após a análise dos três workshops realizados, propõe-se cinco diretrizes como contribuição para exercícios e workshops para a prática crítica:

i. Definir procedimentos de entrega estritos. Diretriz relacionada com a qualidade e a conformidade das entregas dos artefatos desenvolvidos ao longo do workshop. Tais delimitações podem se manifestar tanto como diretrizes do briefing de atividade (i.e., i) dar nome aos artefatos; ii) escrever um texto de $x$ linhas explicando o conceito da proposta, iii) entregar um "número x" de projetos, etc.) quanto no fornecimento de templates para o preenchimento dos participantes. Um exemplo funcional de template no workshop da presente pesquisa foi o do mapa mental. Mesmo que os participantes tenham o preenchido de maneiras particulares, por meio dessa entrega foi possível compreender melhor as particularidades dos temas pesquisados pelos designers. Entendese que, a partir da unificação das entregas, o processo de análise e discussão dos dados é facilitado.

ii. Oferecer métodos e ferramentas generativas. Essa diretriz diz respeito à facilitação de processos criativos e ao aproveitamento do tempo disponível para a atividade projetual. Todo o processo de Fabiana, por exemplo, durou cerca de 45 minutos. Mesmo sendo questionada sobre a possibilidade de utilizar os 75 minutos restantes para o desenvolvimento de novas ideias, Fabiana preferiu não o fazer, encerrando assim, sua atividade de projeto de forma prematura. Mesmo que haja um aspecto pessoal do próprio designer a ser levado em consideração, entende-se que tais dinâmicas poderiam facilitar a geração de novas propostas e, consequentemente, mais dados a serem coletados e analisados posteriormente. Por exemplo, entende-se que a construção de modelos tridimensionais é parte do fazer do designer. Assim, criar condições para modelagens rápidas e simples é uma estratégia possível a ser testada.

iii. Facilitar a colaboração entre os projetistas. A partir da observação dos workshops e no diálogo com os designers, notou-se que a colaboração entre os participantes é benéfica para a atividade projetual: designers acessam novos pontos de vista sobre seus projetos e se auxiliam mutuamente com sugestões e críticas construtivas direcionadas aos projetos dos colegas. Desse modo, defendemos a adoção de dinâmicas colaborativas específicas para que os projetistas interajam entre si e contribuam em discussões e sugestões aos projetos alheios. Tais ações podem se materializar a partir da definição de etapas específicas da atividade (i.e., sessões de críticas às propostas, criação conjunta de artefatos, etc.) e até mesmo na localização de materiais e dos alimentos oferecidos ao longo do workshop (como forma de estímulo e facilitação de relações interpessoais entre os participantes).

iv. Utilizar linguagem clara e compreensível. À primeira vista, essa parece ser uma diretriz 
óbvia e dispensável. No entanto, ao considerar que a prática crítica ainda não é um tema difundido e acessível à grande maioria dos designers, é necessário que o organizador de exercícios que envolvem a criação de artefatos críticos na exploração de problemas de pesquisa, dê atenção especial para os termos que permeiam e direcionam a atividade. Comumente, workshops são intervenções desenvolvidas em curtos períodos de tempo, o que reforça a necessidade que a linguagem apresente termos despidos de ambiguidade para o bom andamento das dinâmicas. Essa diretriz pode ser utilizada tanto na apresentação dos conteúdos - tais como os preceitos teóricos da prática crítica - , quanto nas diretrizes que compõe o briefing do exercício ("Explorar o problema de pesquisa por meio de artefatos críticos" em detrimento de "Investigar o problema de pesquisa [...]", por exemplo). Deve-se estar atento, no entanto, para um balanço que preconize tanto a clareza dos conteúdos, quanto o aspecto generativo inerente da atividade projetual.

v. Facilitar o uso da teoria como validação e como gatilho. Essa diretriz responde ao movimento dos designers na utilização das teorias críticas como validação/gatilhos de suas propostas. Para beneficiar essa dinâmica, sugere-se o desenvolvimento de materiais que transformem as abordagens críticas em diretrizes consistentes de projeto ou até mesmo checklists, em que o designer pode se apoiar para identificar se o artefato desenvolvido carrega ou não características críticas que respondam à teoria.

Para futuros estudos, indicamos a aplicação das diretrizes sugeridas, a fim de testar a eficácia das mesmas.

É importante frisar, enfim, que o presente artigo não busca pela domesticação da prática crítica, apesar de que a proposição de diretrizes possa sugerir esse caminho. Compreendemos e valorizamos seu caráter crítico, questionador e provocativo e colocar amarras em tais atitudes acabaria por descaracterizar tal abordagem. Contudo, entendemos que as diretrizes sugeridas nessa seção podem guiar exercícios introdutórios sobre a prática crítica, facilitando a compreensão da teoria e sua aplicação por aqueles ainda não familiarizados com as características dessa maneira não usual de projetar. Nesse sentido, o buscamos é que esses apontamentos possam funcionar como uma fundação bem estruturada para que aqueles que se sentirem impelidos a seguir com o desenvolvimento de artefatos críticos, o façam de forma mais livre e generativa possível. Qualquer estratégia de projeto que seja sugerida deve antes de tudo estar fundamentada na necessária liberdade criativa do projeto. Uma diretriz é a sugestão de um caminho. O caminho propriamente dito, porém, caberá ao próprio designer construí-lo.

\section{Referências}

AUGER, J. Speculative design: crafting the speculation. Digital Creativity, v. 24, n. 1, p. 11-35, mar. 2013.

BARDZELL, J.; BARDZELL, S.; STOLTERMAN, E. Reading Critical Designs: Supporting Reasoned Interpretations of Critical Design. Proceedings of the 32Nd Annual ACM Conference on Human

Factors in Computing Systems, p. 1951-1960, 2014.

BARDZELL, J.; BARDZELL, S. What is "critical" about critical design? Proceedings of the SIGCHI Conference on Human Factors in Computing Systems - CHI '13, p. 3297, 2013.

BOEHNER, K.; GAVER, W.; BOUCHER, A. Probes. In: Lury, C., \& Wakeford, N. (Eds). (2012). Inventive methods: The happening of the social. London; New York, NY: Routledge 
CARDOSO, R. Design para um Mundo Complexo. São Paulo: Cosac Naify, 2012.

DORST, K. Design research: a revolution-waiting-to-happen. Design Studies, v. 29, n. 1, p. 4-11, 2008.

DUNNE, A. Hertzian Tales: Electronic Products, Aesthetic Experience, and Critical Design. Cambridge: The MIT Press, 2005.

DUNNE, A; RABY, F. Speculative Everything: Design, Fiction, and Social Dreaming. The MIT Press, 2013.

FERRI, G. et al. Analyzing critical designs. Proceedings of the 2014 conference on Designing interactive systems - DIS '14, p. 355-364, 2014.

FLUSSER, V. O Mundo Codificado. São Paulo: Cosac Naify, 2007.

FRANZATO, C. Design as Speculation. Design Philosophy Papers, v. 9, n. 1, p. 23-39, 29 mar. 2011b.

HALPERN, M.; DA COSTA, F. C. X. Workshop e o Design participativo: Uma perspectiva da colaboração designer-cliente. Suldesign Científico - Encontro Sul-Americano de Design, v. 4, n. 1, p. 94, 28 set. 2017.

KRIPPENDORFF, K. The Semantic Turn: A New Foundation for Design. New York: Taylor\&Francis, CRC Press, 2005.

LORENZ, B. Pesquisa Através do Design e Prática Crítica: uma investigação sobre o desenvolvimento de artefatos críticos no processo de construção de problemas de pesquisa acadêmicos. Dissertação (Dissertação em design) - UNISINOS. Porto Alegre, p. 204. 2018.

MALPASS, M. Between Wit and Reason: Defining Associative, Speculative, and Critical Design in Practice. Design and Culture, v. 5, n. 3, p. 333-356, 2013.

MALPASS, M. Critical Design in Context: History, Theory, and Practices. $1^{\mathrm{a}}$ ed. Londres: Bloomsbury Publishing, 2017.

Mazé, R., \& Redström, J. 2007. Difficult forms: Critical practices of design and research. Proc. of IASDR'07.

OZKARAMANLI, D.; DESMET, P. M. A. Provocative design for unprovocative designers: Strategies for triggering personal dilemmas. DRS 2016: Design + Research + Society Future-Focused Thinking. Anais...2016

SCALETSKY, C. C. Pesquisa aplicada/pesquisa acadêmica: o caso Sander. In: CONGRESSO BRASILEIRO DE PESQUISA \& DESENVOLVIMENTO EM DESIGN, 8., 2008, São Paulo. Anais. São Paulo: Centro Universitário SENAC, 2008. p. 1132-1145. 